\title{
Short communication: Animal-level factors associated with whether a dairy female is mated to a dairy or beef bull
}

\author{
D. P. Berry ${ }^{1 *}$ (1) and S. C. Ring ${ }^{2}$ \\ ${ }^{1}$ Teagasc, Animal \& Grassland Research and Innovation Centre, Moorepark, Fermoy P61 P302, Co. Cork, Ireland \\ ${ }^{2}$ Irish Cattle Breeding Federation, Highfield House, Shinagh, Bandon P72 X050, Co. Cork, Ireland
}

\begin{abstract}
When serving a female, the producer must decide whether to mate her to a dairy or beef bull. Tools assisting in this decision could be a useful component of the decision process. A database of 2,283,100 artificial inseminations from 806,725 dairy females was used to investigate what factors were associated with servicing a given female to a beef bull. The probability of being inseminated with a beef bull increased with each service and as the breeding season progressed. An older cow had greater odds of being served with a beef bull, as did cows that calved later in the year, had recently experienced dystocia, were a longer time calved, or were of a poor overall genetic merit compared with herdmates. Cows with low somatic cell count in the previous lactation compared with herdmates were less likely to be mated to a beef bull, as were cows that yielded relatively higher milk solids in the previous lactation. Relative to a first-parity cow, the odds of a fifth-parity cow being mated to a beef bull were 1.35, whereas those of a tenth-parity cow were 2.11 . The odds of a female in the worst $10 \%$ for total genetic merit being mated to a beef bull were 2.90 times those of a female in the top $10 \%$. Although dystocia was associated with the likelihood of being mated to a beef bull, the actual likelihood did not vary much by level of dystocia experienced. Relative to the first service, the odds of the third and fifth services being to a beef bull were 2.23 and 3.71 , respectively. These probability estimates can form the back-end system supporting decisions on mating type for a female within a sire mating advice system but also in risk analysis of farm management.
\end{abstract}

Key words: dairy-beef, beef mating, risk, mating advice

Received January 8, 2020.

Accepted May 7, 2020.

*Corresponding author: donagh.berry@teagasc.ie

\section{Short Communication}

The ability to aid decision making in any enterprise, including dairy production, can be invaluable. Such a benefit forms the basis of decision support tools, which include software systems that support making better decisions faster. One such decision support tool in dairy production is sire mating advice (Pryce et al., 2012; Sun et al., 2013; Carthy et al., 2019), which recommends which bulls to mate to a given female. Carthy et al. (2019) documented how a decision support tool for cattle could operate when selecting which dairy bull to mate to which dairy females. However, the requirement to mate dairy males to a large proportion of dairy females is reducing on many farms as reproductive performance improves (Berry et al., 2014), as herd expansion slows, or as sexed semen with dairy bulls becomes the norm (Seidel et al., 2014). Berry et al. (2019) presented a framework for an index to identify beef bulls that are more suited for mating to dairy females; it is anticipated that once sufficient dairy-bred females have been generated on a farm, the remainder of the dairy female herd will be mated to beef bulls to increase the value of the resulting calves. Therefore, some form of module for a sire mating advice tool is required to inform which females should be mated to a dairy versus a beef bull. Once that decision is made, the dairy sire team can be selected based on criteria such as the total merit index (Cole and VanRaden, 2018; Roche et al., 2017), whereas the beef bull team can be selected based on the dairy-beef index (Berry et al., 2019). To our knowledge, no cattle-based study exists in the scientific literature on the factors associated with whether a dairy female is mated to a beef or a dairy bull.

The objective of the present study was to use a multiple regression model to identify the factors associated with the likelihood of a dairy female being mated to a beef bull versus being mated to a dairy bull. Because the model solutions are to be generated within the framework of a multiple regression model, the predictive probability of a dairy female being mated to a beef bull can be produced for all females depending on their 
individual factors by simply summing the appropriate model solutions. These probability criteria could form the back-end system supporting a decision on which mating type per female within a decision support tool such as a sire mating advice system. Such a mating advice tool could consider the history of calving difficulty of the dairy cow; it may initially use the expected calving date of the cow to predict her expected breeding date but should also be dynamic, with model solutions for that specific cow invoked once she is detected in estrus, thus providing advice on the mating type. However, of particular importance here, as with any descriptive analysis, is that what has happened historically in relation to bull choices may not actually represent best practice. Instead, the model solutions estimated in the present study could be useful in risk analysis of farm management.

All cattle data used in the present study were sourced from the Irish Cattle Breeding Federation (http:/ /www .icbf.com) national database. Phenotypic data were available on 3,694,064 AI records from 6,358 springcalving dairy herds between the years 2014 and 2019, inclusive; the median herd size was 88 females. All herdyears undertook at least 25 inseminations, and at least $70 \%$ of the cows that calved the following year (except for 2019 matings because no data were yet available on 2020 calvings) were mated at least once to an AI sire. Information was available on breed and parity of the cow, date of calving, date of service, extent of dystocia for each calving event, and the service sire identifier (and breed). Dystocia in Ireland is voluntarily recorded by cattle producers on a 1-to-4 scale as (1) no assistance, (2) assistance provided with some calving difficulty, (3) assistance provided with considerable calving difficulty but without veterinary intervention, and (4) assistance provided with considerable calving difficulty resulting in veterinary intervention. Total 305-d lactation milk solids yield and geometric mean lactation SCC were also available for all cows in the data set from herds participating in routine milk testing.

National genetic evaluations were available for the Irish national dairy total net merit index, the Economic Breeding Index (EBI; Roche et al., 2017), from the genetic evaluation immediately before the start of the breeding season for the years 2014 to 2019. Each year's genetic evaluation was merged to the respective service data for that year so that the prevailing genetic merit of the female was available. The genetic merit of the female is likely to change over time, but of interest in the present study was the genetic merit of the female when the breeding decision was being made.

Irish dairy herds operate a strict seasonal calving (and breeding) system (Berry et al., 2013). Dairy bulls tend to be more heavily used in the early period of the breeding season, whereas beef bulls are used in the latter part of the breeding season (Berry et al., 2020a). The breeding season was defined for each herd separately in the present study using the procedure described in detail by Berry et al. (2013) for Irish dairy herds. The breeding season began when 5 cows were served within $14 \mathrm{~d}$ of an initial service. The breeding season terminated when a service to an individual cow was not followed by a subsequent service to any other cow in the herd within the following $21 \mathrm{~d}$. Only breeding seasons between 35 and $140 \mathrm{~d}$ in length were considered where there were more than 20 cows per breeding season. Some herds serve all females in estrus in the early periods of the breeding season only to dairy semen; for inclusion in the present study, the only breeding seasons retained were those where the first service to a beef bull was at least $7 \mathrm{~d}$ before the last service to a dairy bull. Berry et al. (2020a) presented the distribution of dairy and beef services by week of the year for Irish dairy herds. A total of 2,283,100 insemination records from 806,725 females in 4,944 herds remained. A variable was defined within herd, representing the time period of the breeding season when the insemination was undertaken, with each time period being one-fifth of the breeding season. Days since calving when served was defined for each cow as $\leq 30 \mathrm{~d}, 31$ to $60 \mathrm{~d}, 61$ to $90 \mathrm{~d}$, . . ., 151 to 180 $\mathrm{d}$, and $>180 \mathrm{~d}$; maiden heifers were coded separately. Service number was recoded as $1,2,3,4$, and $5+$.

Female EBI was stratified within each herd breeding season into 10 equal-sized groups. An EBI group representing missing information was also allocated to facilitate the inclusion of these records in the subsequent analysis; $4.5 \%$ of the inseminations were allocated to the missing EBI group. Cattle generally are missing an EBI where parentage is unknown or at least not recorded. Milk solids yield and mean SCC in the previous lactation were both individually stratified within each herd breeding season into 10 equal-sized groups, with an additional group allocated to those with no milk solids yield or SCC in the previous lactation (i.e., heifers or cows that were not milk tested).

The association between a series of potential risk factors and the logit of the odds of being mated to a beef bull was quantified in ASReml (Gilmour et al., 2009) using a threshold model accounting for the binomial distribution of the data. Risk factors considered in the multiple regression model were parity of the female, period since calving, period of the breeding season, calendar week of calving, service number, stratum of genetic merit on EBI, stratum of 305-d milk solids yield in the previous lactation, stratum of 305-d geometric mean SCC in the previous lactation, calving difficulty in the 
current lactation, and the breed covariates representing Jersey, Norwegian Red, Montbéliarde, and "other"; Holstein-Friesian breed proportion was omitted from the model. Contemporary group represented by the breeding season of that herd-year was included as a fixed effect in the model, and cow was included as a random effect. Also of interest was whether the detected associations differed by parity; this was investigated by quantifying the significance of 2 -way interaction terms in the models that included parity number. The reference service used for the derivation of predicted probabilities was the first service of a third-parity cow that calved in the tenth calendar week of the year with no calving difficulty, of median EBI, median milk solids yield, median SCC, served in the middle of the breeding season, and calved 61 to $90 \mathrm{~d}$; this would be considered an average mature Irish dairy female.

The mean percentage of dairy females in the edited data set mated to a beef bull was $24.5 \%$; this is not reflective of the national mean because the sample population included only females that were documented as mated to an AI bull and included only herds that used beef semen in their breeding program. Of the calves born in Ireland in 2018 to Holstein-Friesian dams, $45 \%$ were recorded to have been sired by a beef bull (DAFM, 2018). Irrespective of other terms in the model, the probability of a female being inseminated with a beef bull increased $(P<0.001)$ with each service number and as the breeding season progressed. Older cows had greater $(P<0.001)$ odds of being served with a beef bull, as did cows that calved later in the year or had recently experienced a dystocia; cows that were of a poor overall total merit index (i.e., EBI) relative to herdmates or were a longer time calved also had greater $(P<0.001)$ odds of being served with a beef bull. Cows with low SCC in the previous lactation relative to herdmates were less $(P<0.001)$ likely to be mated to a beef bull, as were cows that yielded high milk solids in the previous lactation relative to contemporaries. Although the association between EBI, dystocia, period of the breeding season, service number, and days calved all differed $(P<0.001)$ by parity number, the trends were all the same across parity number, and thus, only the main effects are discussed. Relative to a purebred Holstein-Friesian, the logit of the probability of a purebred Jersey, Montbéliarde, or Norwegian Red female being mated to a beef bull was $-0.52(\mathrm{SE}=0.027), 0.91(\mathrm{SE}$ $=0.05)$, and $0.20(\mathrm{SE}=0.05)$, respectively. In expected probability terms, this equates to the probability of a first-generation $\left(\mathbf{F}_{1}\right)$ Jersey $\times$ Holstein-Friesian being mated to a beef bull being 4 percentage units lower than that of a Holstein-Friesian female, whereas the probability of an $\mathrm{F}_{1}$ Montbéliarde $\times$ Holstein-Friesian or $\mathrm{F}_{1}$ Norwegian Red $\times$ Holstein-Friesian being mated to a beef bull was 9 percentage units and 2 percentage units higher, respectively, compared with a HolsteinFriesian female. The inferior carcass credentials of Jersey (cross) animals relative to Holstein-Friesians have already been established (Berry et al., 2018), as have the superior milk production characteristics of the Jersey crossbred (Coffey et al., 2016), implying that such cow types are more suitable for dairy production than for beef production.

The probability of being served to a beef bull increased consistently from a heifer to a tenth-parity cow (Figure 1); relative to a first-parity cow, the odds of a fifth-parity cow being mated to a beef bull were 1.35, whereas those of a tenth-parity cow were 2.11 . If genetic gain is occurring in a herd, the youngest animals should be the most elite, and thus, producers tend to use these as parents of the next generation. However, genetic merit was also included in the multiple regression model to negate this effect; as expected, the probability of being mated to a beef bull reduced as EBI increased, indicating that producers were, on average, mating their higher genetic merit females to dairy semen with the intent of retaining the resulting females as herd replacements. Even after adjusting for everything in the multiple regression model, the odds of a female in the worst $10 \%$ for EBI being mated to a beef bull were 2.9 times those of a female in the top $10 \%$ on EBI (Figure 1); this equated to a difference in probability for the reference female of 21 percentage units. Based on a univariate analysis of parity alone (as well as adjusting for contemporary group and animal as a random effect), the odds of a fifth-parity cow being mated to a beef bull relative to a first-parity cow were 2.73 and those of a tenth-parity cow were 4.31. These univariate model solutions, compared with those from the multiple regression, confirm that genetic merit of the younger animals is a factor being considering when deciding what bull to mate to different parity animals, but it is not the only reason.

Although milk solids yield in the previous lactation was associated with the likelihood of being mated to a beef bull, the trend was not consistent across yield strata, other than a tendency for higher yielding cows to be less likely to be mated to beef bulls (Figure 1). Similarly, the odds of being mated to a beef bull differed little across strata of SCC, except for the lower likelihood in the lowest SCC strata. This implies that milk solids yield or SCC in the previous lactation does not have any strong systematic effect on whether the female will be mated to a dairy or beef bull. Even when the model included only milk solids or SCC (along with contemporary group and a random animal effect), there 
(a)

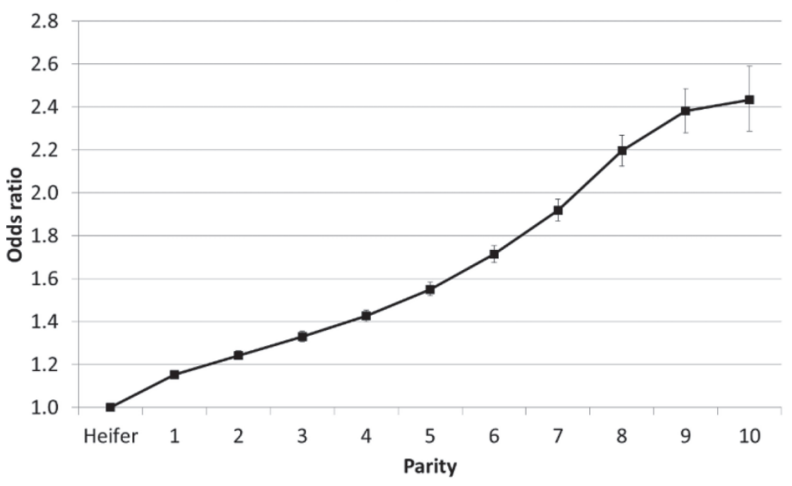

(b)

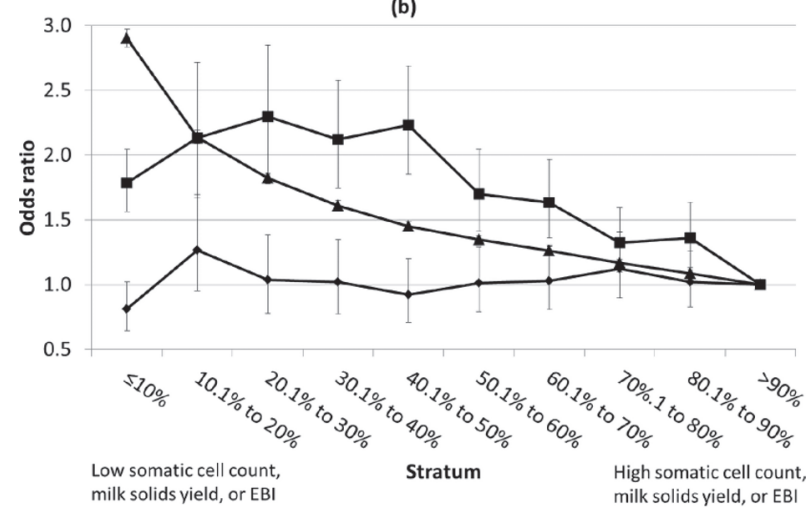

(c)

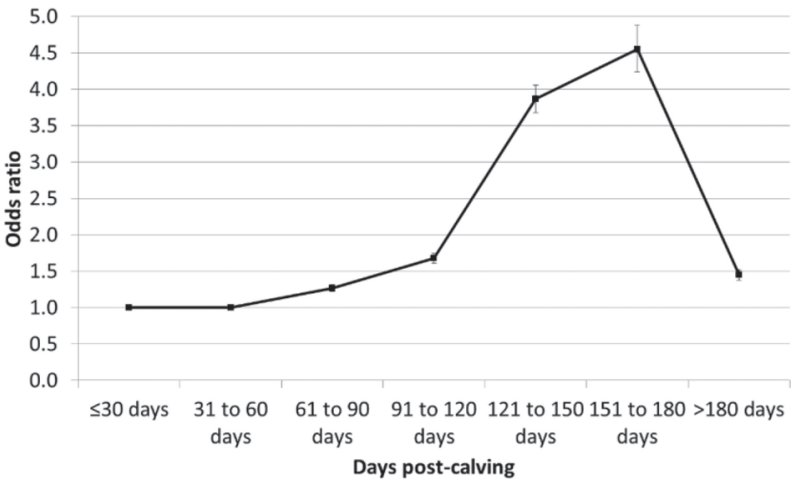

(d)

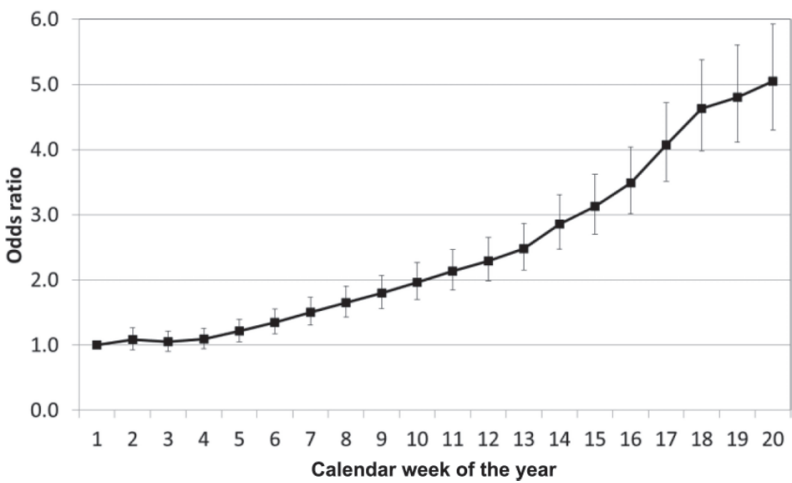

Figure 1. Odds ratios (including 95\% CI) of being served to a beef bull by (a) parity, (b) stratum [triangles = Economic Breeding Index (EBI), squares = milk solids yield in the previous lactation, diamonds = SCC in the previous lactation], (c) days postcalving when served, and (d) calendar week of the year when calved, where wk 1 is the first week of January. 
was no consistent trend with either variable. Although both milk solids yield and SCC constitute the EBI, results from the present study imply that producers, on average, focus more on the EBI of a female rather than her phenotypic milk production performance when making mating decisions.

The odds of being mated to a beef bull did not change with days postcalving when served up to $90 \mathrm{~d}$, after which they increased sharply (Figure 1); relative to cows that were served within $60 \mathrm{~d}$ of calving, cows served 151 to $180 \mathrm{~d}$ postcalving were $>4.5$ times more likely to be inseminated with a beef bull. The odds of being served with a beef bull increased almost consistently with each calendar week later at calving (Figure 1). Relative to the first service, the odds of the third and fifth service being to a beef bull were 2.23 and 3.71, respectively (Table 1 ). Irish dairy farmers tend to use dairy bull semen in the early period of the breeding season, followed by beef semen (Berry et al., 2020a); this is consistent with the odds ratios estimated in the present study for the different periods of the breeding season (Table 1). Once the service was undertaken in the final two-fifths of the breeding season, the odds of the female being mated to a beef bull were $>20$ times those compared with the service undertaken in the first fifth of the breeding season. It is important that a female replacement calf is born early in the calving season so that it will be the appropriate age for calving early in the season $2 \mathrm{yr}$ later. This is paramount to profitable seasonal production systems that exist in Ireland (Berry et al., 2013) and elsewhere (Grosshans et al., 1997); milk production is compromised in cows

Table 1. Model solutions (b) and respective odds ratios (OR) for different levels of dystocia at the previous calving, service number, and period of the breeding season when served

\begin{tabular}{lll}
\hline Condition & $\mathrm{b}(\mathrm{SE})$ & $\mathrm{OR}(95 \% \mathrm{CI})$ \\
\hline $\begin{array}{l}\text { Dystocia level } \\
\text { No assistance }\end{array}$ & 0 & 1 \\
Slight assistance & $0.09(0.01)$ & $1.09(1.07,1.12)$ \\
Severe assistance & $0.15(0.02)$ & $1.16(1.11,1.21)$ \\
$\quad$ Vet assistance & $0.31(0.04)$ & $1.36(1.24,1.48)$ \\
Service number & & \\
1 & 0 & 1 \\
2 & $0.29(0.01)$ & $1.34(1.32,1.35)$ \\
3 & $0.80(0.01)$ & $2.23(2.19,2.28)$ \\
4 & $1.10(0.02)$ & $3.00(2.87,3.12)$ \\
$5+$ & $1.31(0.04)$ & $3.71(3.44,4.01)$ \\
Period of breeding & & \\
season & & 1 \\
First fifth & 0 & $2.09(2.07,2.12)$ \\
Second fifth & $0.74(0.01)$ & $6.99(6.87,7.11)$ \\
Third fifth & $1.94(0.01)$ & $20.76(20.31,21.22)$ \\
Fourth fifth & $3.03(0.01)$ & $45.51(44.29,46.77)$ \\
Last fifth & $3.82(0.01)$ & \\
\hline
\end{tabular}

calving younger than 24 mo of age (Berry and Cromie, 2009). Being born early in a calving season is conditional on conception early in the previous breeding season. Therefore, the period of the breeding season when the mating occurs is an obvious factor affecting the decision of whether the service is to a dairy (i.e., to generate a potential female replacement) or a beef bull.

Although calving dystocia was associated with the likelihood of being mated to a beef bull, the actual likelihoods did not vary much by the level of calving dystocia experienced (Table 1); a cow that required veterinary assistance was 1.36 times $(P<0.001)$ more likely to be mated to a beef bull than a dairy bull compared with a cow that did not require assistance at calving. This equated to a difference of just 6 percentage units in the probability of being mated to a beef bull for cows that required veterinary assistance versus those that experienced no assistance. In the present study, $8 \%$ of cows that did not require assistance at the most recent calving were mated to an Angus bull, whereas this increased to $13 \%$ if the cow had required veterinary assistance at calving. In Ireland, the mean direct calving difficulty genetic merit of Angus bulls when mated to cows is less (i.e., easier) than that of Holstein-Friesians (Berry and Ring, 2020b).

The results generated in the present study can be useful default parameters for inclusion in decision support mating advice tools (Pryce et al., 2012; Sun et al., 2013; Carthy et al., 2019). These parameters can be used in conjunction with decision support tools that identify females suitable for culling (Kelleher et al., 2015). Combined, the females on a given farm can be allocated to culling (from culling index proposed by Kelleher et al., 2015), breeding to a beef bull (based on the probabilities calculated in the present study), or for consideration as a parent of the next generation of dairy females. For example, assuming the same team of dairy bulls, a potential dam with lower genetic merit has a higher probability of producing a genetically inferior replacement female and thus does not generally merit consideration as a female to generate herd replacements, unless insufficient replacements are expected to be generated. This female should be mated to a beef bull and either a web-service mating advice program or cow-side electronic system used at insemination can be populated with such information to help the decision making. The parameters estimated in the present study probably do not contribute much to this relatively clear-cut decision. However, the model solutions derived in the present study are most useful for dams of average genetic merit where a decision has to be made as to whether they should be mated to a dairy or a beef bull. Important here is that the 
probability estimates are live and updated as new information becomes available (e.g., service number) but also consider the likelihood that sufficient dairy females will be available to replace the females being culled (or die) in the following 12 mo. It should nonetheless be acknowledged that these base parameters contributing to the estimated probabilities are not based on risk analysis assessments but on what was decided a priori with arguably poor awareness. In fact, the estimated odds and ranges in probability could be useful to rank criteria of farmer decision choices, to support economic assessment of the mating decision process, and to run future risk analysis and scenarios.

The model solutions can also be used for planning or even retrospectively monitoring genetic gain achieved on farm. From a planning perspective, the type of female that is likely to be mated to a beef bull, coupled with the known mean genetic merit of the bull used for that female (e.g., mean sire genetic merit for carcass weight for each cow parity; Berry et al., 2020a), can be used to predict the expected beef output from the farm and when it will be born; carcasses from younger cows are lighter (Judge et al., 2019). This can be projected at the level of the herd or nationally. Similarly, based on the converse of the probability of being mated to a beef bull, the expected genetic merit of the dairy replacement females in the next generation, and when in the calving season they are likely to be born, can be predicted once the team of dairy bulls is known; deviations from these predictions can then be identified and troubleshot.

In conclusion, evidence exists of a relatively strong preference to which females are mated to beef bulls relative to dairy bulls. Although this information is useful in the modeling of different farm-level management systems, it can also provide useful baseline default parameters for mating advice decision support tools and risk assessments. These tools should be sufficiently dynamic and integrated within the breeding and farm information and communications technology infrastructure to change as the cow and herd parameters change (e.g., cow service number). Although the model solutions can be used to advise on whether a beef or dairy bull is most appropriate for a given female, the next logical step, through sire mating advice, is to choose which dairy or beef bull. Such systems exist for recommending dairy $\times$ dairy matings (Carthy et al., 2019), but there is a lack of decision support tools for advising on which beef bulls to mate to which dairy females. It should be noted that the data used in the present study related to strict seasonal calving herds, and although some factors such as period of the breeding season when served are not relevant in year-round calving systems, other factors such as cow age, genetic merit, and previous lactation performance are likely to persist. Notwithstanding, it does merit investigation in year-round calving systems that exist in other countries.

\section{ACKNOWLEDGMENTS}

This publication has emanated from research supported by a research grant from Science Foundation Ireland and the Department of Agriculture, Food and Marine (Dublin, Ireland) on behalf of the government of Ireland under the grant 16/RC/3835 (VistaMilk), as well as the Research Stimulus Fund Dairy4Beef. The authors have not stated any conflicts of interest.

\section{REFERENCES}

Berry, D. P., P. R. Amer, R. D. Evans, T. Byrne, A. R. Cromie, and F. Hely. 2019. A breeding index to rank beef bulls for use on dairy females to maximize profit. J. Dairy Sci. 102:10056-10072. https:/ /doi.org/10.3168/jds.2019-16912.

Berry, D. P., and A. R. Cromie. 2009. Associations between age at first calving and subsequent performance in Irish spring calving Holstein-Friesian dairy cows. Livest. Sci. 123:44-54. https://doi .org/10.1016/j.livsci.2008.10.005.

Berry, D. P., M. J. Judge, R. D. Evans, F. Buckley, and A. R. Cromie. 2018. Carcass characteristics of cattle differing in Jersey proportion. J. Dairy Sci. 101:11052-11060. https://doi.org/10.3168/jds .2018-14992.

Berry, D. P., J. F. Kearney, K. Twomey, and R. D. Evans. 2013. Genetics of reproductive performance in seasonal calving dairy cattle production systems. Ir. J. Agric. Food Res. 52:1-16.

Berry, D. P., and S. C. Ring. 2020b. Observed progeny performance validates the benefit of mating genetically elite beef sires to dairy females. J. Dairy Sci. 103:2523-2533. https://doi.org/10.3168/jds .2019-17431.

Berry, D. P., S. C. Ring, A. J. Twomey, and R. D. Evans. 2020a Choice of artificial insemination beef bulls used to mate with female dairy cattle. J. Dairy Sci. 103:1701-1710. https://doi.org/10 $.3168 /$ jds.2019-17430.

Berry, D. P., E. Wall, and J. E. Pryce. 2014. Genetics and genomic of reproductive performances in dairy and beef cattle. Animal 8(Suppl. 1):105-121. https://doi.org/10.1017/S1751731114000743.

Carthy, T. R., J. McCarthy, and D. P. Berry. 2019. A mating advice system in dairy cattle incorporating genomic information. J. Dairy Sci. 102:8210-8220. https://doi.org/10.3168/jds.2019-16283.

Coffey, E. L., B. Horan, R. D. Evans, and D. P. Berry. 2016. Milk production and fertility performance of Holstein, Friesian, and Jersey purebred cows and their respective crosses in seasonal-calving commercial farms. J. Dairy Sci. 99:5681-5689. https://doi.org/10 $.3168 /$ jds.2015-10530.

Cole, J. B., and P. M. VanRaden. 2018. Symposium review: Possibilities in an age of genomics: The future of selection indices. J. Dairy Sci. 101:3686-3701. https://doi.org/10.3168/jds.2017-13335.

DAFM (Department of Agriculture, Food and the Marine). 2018. AIM Bovine Statistics Report 2018. AIM Division, Department of Agriculture, Food and the Marine, Dublin, Ireland.

Gilmour, A. R., B. J. Gogel, B. R. Cullis, R. Thompson, and D. Butler. 2009. ASReml User Guide Release 3.0. VSN Int. Ltd., Hemel Hempstead, UK.

Grosshans, T., Z. Z. Xu, L. J. Burton, D. L. Johnson, and K. L. Macmillan. 1997. Performance and genetic parameters for fertility of seasonal dairy cows in New Zealand. Livest. Prod. Sci. 51:41-51. https://doi.org/10.1016/S0301-6226(97)00104-8. 
Judge, M. M., T. Pabiou, S. Conroy, R. Fanning, M. Kinsella, D. Aspel, A. R. Cromie, and D. P. Berry. 2019. Factors associated with the weight of individual primal cuts and their inter-relationship in cattle. Transl. Anim. Sci. 3:1593-1605. https://doi.org/10.1093/ tas/txz134.

Kelleher, M. M., P. R. Amer, L. Shalloo, R. D. Evans, T. J. Byrne, F. Buckley, and D. P. Berry. 2015. Development of an index to rank dairy females on expected lifetime profit. J. Dairy Sci. 98:42254239. https://doi.org/10.3168/jds.2014-9073.

Pryce, J. E., B. J. Hayes, and M. E. Goddard. 2012. Novel strategies to minimize progeny inbreeding while maximizing genetic gain using genomic information. J. Dairy Sci. 95:377-388. https://doi.org/10 $.3168 /$ jds.2011-4254.

Roche, J. R., D. P. Berry, A. M. Bryant, C. R. Burke, S. T. Butler, P. G. Dillon, D. J. Donaghy, B. Horan, K. A. Macdonald, and K.
L. Macmillan. 2017. A 100-year review: A century of change in temperate grazing dairy systems. J. Dairy Sci. 100:10189-10233. https://doi.org/10.3168/jds.2017-13182.

Seidel, G. E. Jr. 2014. Update on sexed semen technology in cattle. Animal 8(Suppl. 1):160-164. https://doi.org/10.1017/ S1751731114000202.

Sun, C., P. M. VanRaden, J. R. O'Connell, K. A. Weigel, and D. Gianola. 2013. Mating programs including genomic relationships and dominance effects. J. Dairy Sci. 96:8014-8023. https://doi .org/10.3168/jds.2013-6969.

\section{ORCIDS}

D. P. Berry ๑ https://orcid.org/0000-0003-4349-1447 